\title{
The Progress of the Visual Field in Chronic Simple Glaucoma and Ocular Hypertension Treated Topically with Pilocarpine or with Timolol
}

\author{
R. P. CRICK, ${ }^{1}$ R. B. NEWSON,${ }^{2}$ M. J. SHIPLEY, ${ }^{2}$ H. BLACKMORE,${ }^{4}$ AND C. J. \\ BULPITT. $^{2}$
}

London

\begin{abstract}
Summary
It is theoretically possible that the vascular effects of topical sympathetic betablocking therapy in chronic simple glaucoma (CSG) might tend to neutralise the beneficial effect of a reduced intraocular pressure on the preservation of the visual field. We therefore followed the progress of 422 right eyes and 420 left eyes of 483 patients with CSG and 119 right eyes and 132 left eyes of 151 patients with an original diagnosis of ocular hypertension $(\mathrm{OH})$. These patients were observed for a minimum of one year and up to 13 years, being followed for an average period of 5.1 years in the case of CSG and of 4.5 years in $\mathrm{OH}$. The majority of eyes with CSG were treated topically with a miotic and $38 \%$ of these received beta blocking therapy in the form of topical timolol.

It was concluded that despite suggestions that beta blockers might reduce vascular perfusion of the optic nerve head, which might in turn cause an adverse effect on the visual field progress, the results of this analysis showed that there was less mean deterioration of visual field in eyes treated with beta blocker plus miotic treatment compared with those on miotic therapy alone.
\end{abstract}

In an attempt to assess the visual field progress in patients with chronic simple glaucoma (CSG) and ocular hypertension (OH) treated with a number of therapeutic agents, particularly topical pilocarpine and timolol, the analysis of the computerized Glaucoma Data base at King's College Hospital was extended. ${ }^{1,2}$ $\mathrm{CSG}$ and $\mathrm{OH}$ refer to the original diagnosis made using the criteria adopted by Hollows and Graham for the Ferndale Survey. ${ }^{3}$ This paper reports the result of analyses aimed at measuring and comparing the influence of topical treatment with either pilocarpine alone or timolol and pilocarpine on the progress of the visual field.

This is a prospective study as the data base was designed to examine the factors affecting visual field progress in patients with CSG and $\mathrm{OH}$ but within the constraints imposed by the resources available and current management methods.

\section{Patients and Methods}

In this 13 year investigation 422 right eyes and 420 left eyes of 483 patients with chronic simple glaucoma were followed for an aver- 


\section{K.C.H. COMPUTERISED DATA BASE METHOD OF VISUAL FIELD REPRESENTATION (APPUED TO FRIEDMANN ANALYSER)}
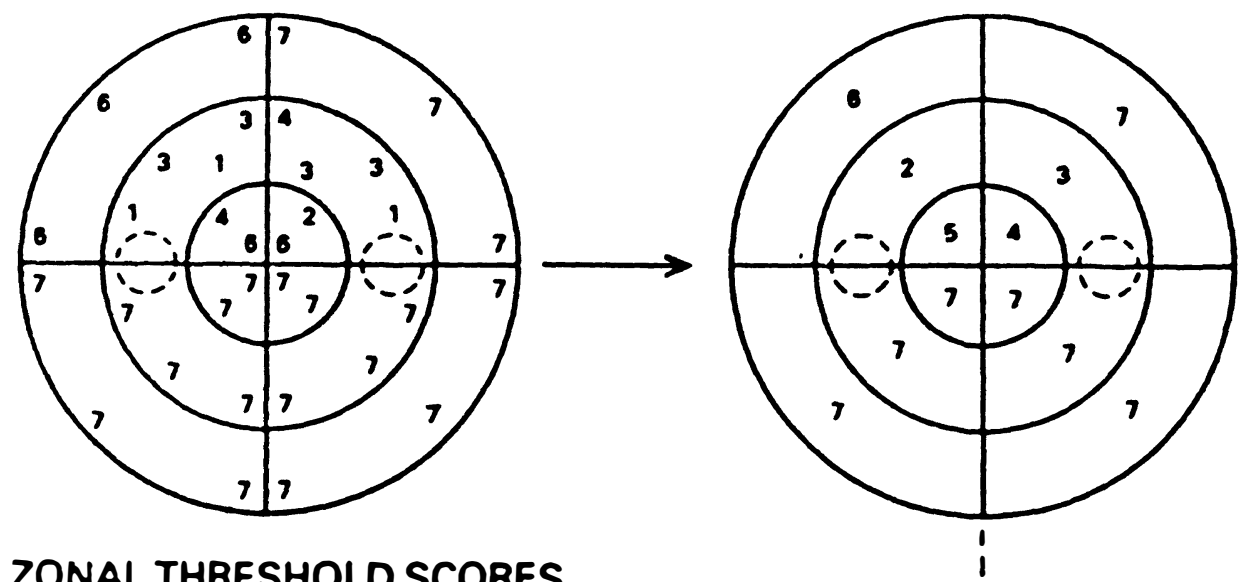

\section{ARE RECORDED AS A 'FIELD CROSS' UNITS ARE $(4 \mathrm{~dB}+1)$}

THE ZONAL THRESHOLD SCORES
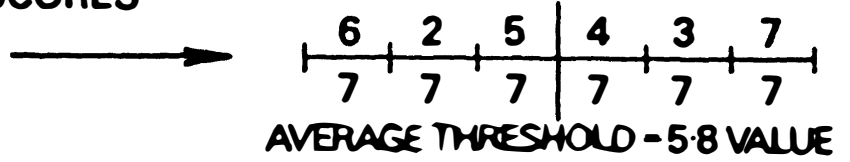

\section{EACH QUADRANT OF THE FIELD IS DIVIDED INTO 3 ZONES INNER $0^{\circ}-10^{\circ}$, MIDDLE $10^{\circ}-20^{\circ}$, OUTER $20^{\circ}-30^{\circ}$}

Fig. 1. Field cross method of visual field representation.

age of just over five years and 119 right eyes and 132 left eyes of 151 patients with ocular hypertension were followed for an average of 4.5 years.

The progress of visual fields using the Friedmann Visual Field Analyser was followed by the method described previously by $\mathrm{Crick}^{1}$ (Fig. 1) using a calculated visual field coefficient (VFC) to measure the average threshold sensitivity of a number of loci tested in a specified area of the visual field expressed in units of $(4 \mathrm{db}+1) \times 10$. In this case the average threshold sensitivity expressed as a Visual Field Coefficient (VFC) throughout the $30^{\circ}$ visual fields was calculated.

Exclusions were made for the following reasons:

(1) Less than two dated follow up visual fields.

(2) Less than one year between first and last follow up visual fields.

(3) Age and sex unrecorded.

(4) Unknown duration of beta blocker or miotic treatment in the time between first follow up visual field and last follow up visual field.

\section{Statistical Methods}

The Visual Field Coefficient (VFC) gives a measure of the average threshold sensitivity of all the loci tested in the visual field examined. One of the simplest ways of estimating the progress of the visual field is to subtract the last VFC from the first and to divide the result by the number of years of follow up to give the change per year. We call this the overall (unadjusted) change in VFC per year. Four eyes were excluded with annual rate of change of visual field coefficient less than -15 or greater than 15 .

As the data record the results of normal clinical work the treatment groups could differ in important respects so that a mathematical model using multiple linear regression techniques was used to express the final follow up VFC in terms of the following variables:

(1)The first follow up VFC.

(2) The total time elapsed in years between 
Table I Unadjusted change in visual field coefficient $\left(S E^{*}\right)$ in right eyes with chronic simple glaucoma according to whether or not treatment was given with miotics or beta blockers at some time. Corresponding presenting and mean treated intraocular pressures in $\mathrm{mmHg}$ are also recorded

\begin{tabular}{|c|c|c|c|c|c|c|c|}
\hline \multirow{3}{*}{\multicolumn{2}{|c|}{ Change in $V F C$}} & \multicolumn{6}{|c|}{ Miotic Therapy } \\
\hline & & \multicolumn{2}{|c|}{ At some time } & \multicolumn{2}{|l|}{ Never } & \multicolumn{2}{|l|}{ Total } \\
\hline & & & $n$ & & $n$ & & $n$ \\
\hline \multirow{3}{*}{ 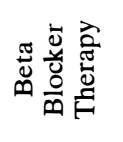 } & $\begin{array}{l}\text { At some } \\
\text { time }\end{array}$ & $\begin{array}{l}-0.64(0.17) \\
* *\end{array}$ & 140 & $-1.68(0.40)$ & 32 & $-0.83(0.16)$ & 172 \\
\hline & Never & $-1.24(0.17)$ & 220 & $-0.54(0.56)$ & 30 & $-1.555(0.16)$ & 250 \\
\hline & Total & $-1.00(0.12)$ & 360 & $-1.13(0.35)$ & 62 & $-1.02(0.11)$ & 422 \\
\hline \multicolumn{8}{|c|}{ Presenting IOP $\mathrm{mm} \mathrm{Hg}$} \\
\hline \multirow{3}{*}{ 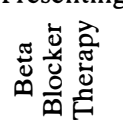 } & $\begin{array}{l}\text { At some } \\
\text { time }\end{array}$ & $24.8(0.6)$ & 139 & $23.2(1.1)$ & 31 & $24.5(0.5)$ & 170 \\
\hline & Never & $22.0(0.6)$ & 208 & $19.5(1.9)$ & 30 & $21.7(0.5)$ & 238 \\
\hline & Total & $23.1(0.4)$ & 347 & $21.4(1.1)$ & 61 & $22.9(0.4)$ & 408 \\
\hline \multicolumn{8}{|c|}{ Mean treated IOP $\mathrm{mm} \mathrm{Hg}$} \\
\hline \multirow{3}{*}{ 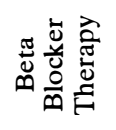 } & $\begin{array}{l}\text { At some } \\
\text { time }\end{array}$ & $19.4(0.2)$ & 137 & $18.5(0.4)$ & 32 & $19.2(0.2)$ & 169 \\
\hline & Never & $18.1(0.2)$ & 206 & $15.5(0.7)$ & 30 & $17.7(0.2)$ & 236 \\
\hline & Total & $18.6(0.1)$ & 343 & $17.0(0.4)$ & 62 & $18.3(0.1)$ & 405 \\
\hline
\end{tabular}

* SE Standard errors (SE) are given in parentheses.

${ }^{* *}$ In the large group a miotic $\mathrm{p}=0.01$ for the difference between those ever given a beta blocker and those never given this treatment.

the first follow up VFC and the final follow up VFC.

(3) The presence or absence of miotic therapy at the time of the first follow up VFC.

(4) The presence or absence of miotic therapy at the time of the final follow up VFC.

(5) The duration in years of various individual treatments between the first follow up VFC and the final follow up VFC.

(6) The age at the time of the first follow up VFC.

(7) Sex.

The aim of the model was to assess the rate of visual field loss under various treatments. The variables three and four were introduced to ensure that the estimation of these rates would not be affected by the reduction in VFC attributable to miosis. The coefficients for variable five singly or in combination with variable two give a measure of the change in VFC per year adjusted for the other terms in the model for subjects on various treatments. We call this measure the change in the adjusted VFC per year.

\section{Results}

\section{(1) Unadjusted change in VFC per year}

(a) Chronic Simple Glaucoma

The unadjusted change in VFC per year for those with chronic simple glaucoma according to whether or not treatment was given with miotics or beta blockers at some time, together with corresponding presenting and mean treated intraocular pressure, is shown in Tables I and II. The data show that for 422 right eyes and 420 left eyes of all the patients treated the calculated mean VFC changed by -1.02 units per year in the right eyes and by -1.12 per year for the left eyes. For those treated at any time with a beta blocker, the calculated change in mean VFC was -0.83 units per year for the right eyes $(n=172)$ and -0.88 units per year for the left eyes $(\mathrm{n}=165)$.

For those treated with miotics at some time the calculated change in mean VFC per year was -1.0 unit for the right eyes $(n=360)$ and -1.1 units for the left eyes $(n=355)$. In those who were treated with miotics and who never received a beta blocker the mean change per year was -1.24 units for right eyes and -1.37 units for the left eyes. However, for those who were treated with both a miotic and a beta blocker the mean annual change was much 
Table II Unadjusted change in visual field coefficient ( $S E^{*}$ ) in left eyes with chronic simple glaucoma according to whether or not treatment was given with miotics or beta blockers at some time. Corresponding presenting and mean treated intraocular pressures in $\mathrm{mmHg}$ are also recorded

\begin{tabular}{|c|c|c|c|c|c|c|c|}
\hline \multirow{3}{*}{\multicolumn{2}{|c|}{ Change in $V F C$}} & \multicolumn{6}{|c|}{ Miotic Therapy } \\
\hline & & \multicolumn{2}{|c|}{ At some time } & \multicolumn{2}{|c|}{ Never } & \multicolumn{2}{|c|}{ Total } \\
\hline & & & $n$ & & $n$ & & $n$ \\
\hline \multirow{2}{*}{ 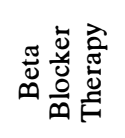 } & $\begin{array}{l}\text { At some } \\
\text { time }\end{array}$ & $-0.64(0.21)$ & 131 & $-1.82(0.54)$ & 34 & $-0.88(0.20)$ & 165 \\
\hline & $\begin{array}{l}\text { Never } \\
\text { Total }\end{array}$ & $\begin{array}{l}-1.37(0.17) \\
-1.10(0.13)\end{array}$ & $\begin{array}{l}224 \\
355\end{array}$ & $\begin{array}{l}-0.59(0.46) \\
-1.23(0.36)\end{array}$ & $\begin{array}{l}31 \\
65\end{array}$ & $\begin{array}{l}-1.27(0.16) \\
-1.12(0.12)\end{array}$ & $\begin{array}{l}255 \\
420\end{array}$ \\
\hline \multirow{2}{*}{ 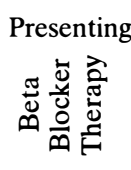 } & $\begin{array}{l}\text { IOP mm } \\
\text { At some } \\
\text { time }\end{array}$ & $24.8(0.7)$ & 124 & $23.7(1.1)$ & 33 & $24.6(0.6)$ & 157 \\
\hline & $\begin{array}{l}\text { Never } \\
\text { Total }\end{array}$ & $\begin{array}{l}22.2(0.6) \\
23.2(0.4)\end{array}$ & $\begin{array}{l}215 \\
339\end{array}$ & $\begin{array}{l}18.1(1.6) \\
21.0(1.0)\end{array}$ & $\begin{array}{l}31 \\
64\end{array}$ & $\begin{array}{l}21.7(0.5) \\
22.8(0.4)\end{array}$ & $\begin{array}{l}246 \\
403\end{array}$ \\
\hline $\begin{array}{l}\text { Mean tre } \\
\text { 包 }\end{array}$ & $\begin{array}{l}\text { ted IOP m } \\
\text { At some } \\
\text { time }\end{array}$ & $19.1(0.3)$ & 128 & $18.6(0.6)$ & 34 & $19.0(0.2)$ & 162 \\
\hline 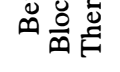 & $\begin{array}{l}\text { Never } \\
\text { Total }\end{array}$ & $\begin{array}{l}18.4(0.2) \\
18.6(0.1)\end{array}$ & $\begin{array}{l}209 \\
337\end{array}$ & $\begin{array}{l}14.1(0.7) \\
16.6(0.5)\end{array}$ & $\begin{array}{l}29 \\
63\end{array}$ & $\begin{array}{l}17.9(0.2) \\
18.3(0.1)\end{array}$ & $\begin{array}{l}238 \\
400\end{array}$ \\
\hline
\end{tabular}

${ }^{*}$ SE Standard errors (SE) are given in parentheses.

** In the large group a miotic $\mathrm{p}<0.05$ for the difference between those ever given a beta blocker and those never given this treatment.

less both for right eyes, $-0.64(\mathrm{n}=140)$ and for the left eyes, $-0.64(n=131)$. The difference between the annual reduction in those given miotics alone and those given miotics plus a beta blocker was statistically significant ( $\mathrm{p}=0.01$ right, $\mathrm{p}<0.05$ left $)$. When considering the group who did not receive a miotic the change with a beta blocker alone was -1.7 units/year (right eyes) and -1.8 units/year (left eyes). However, this small sub-group only included 34 patients and statistically these rates did not differ significantly from those on pilocarpine alone. The relevance of presenting and mean treated intraocular pressure to these findings is considered below.

(b) Ocular Hypertension

Tables III and IV show the unadjusted change in VFC per year and corresponding presenting and mean treated intraocular pressure for 119 right eyes and 132 left eyes diagnosed as $\mathrm{OH}$ on entry to the study, the change in unadjusted mean visual field coefficient per year was -0.63 units for the right eyes and -0.47 units for the left eyes. Of those who received a beta blocker at any time, the right eyes $(n=40)$ showed a mean annual change in VFC of -0.12 units and the left $(n=43)$
-0.34 units. For those who received a miotic at any time the annual rate of change was slightly greater -0.75 right $(n=65)$ and -0.64 left $(n=70)$. Those who received only a miotic showed an annual visual field coefficient change of -1.37 units right eyes $(n=41)$ and -0.78 units left eyes $(n=43)$.

For those ocular hypertensive patients ever given a miotic, those also given a beta blocker at some time had an average change in VFC of -0.43 units per year in the left eyes and an average change of +0.29 units per year in the right eyes. The increase in the right eyes differed significantly from the fall observed in those right eyes only treated with a miotic $(\mathrm{p}<0.05)$. However, statistical significance was not achieved in the left eyes. Intraocular pressure readings and their relevance to visual field changes are considered below.

\section{Adjusted change in VFC/year}

Table $\mathrm{V}$ gives the multiple regression equations when the final VFC was expressed in terms of the first follow up VFC, duration of follow up, age, sex, miotic use at the beginning and end of follow up, the duration of miotic use and the duration of beta blocker use. The first column, for example, gives the 
Table III Unadjusted change in visual field coefficient $\left(S E^{*}\right)$ in right eyes with ocular hypertension according to whether or not treatment was given with miotics or beta blockers at some time. Corresponding presenting and mean treated intraocular pressures in $\mathrm{mmHg}$ are also recorded

\begin{tabular}{|c|c|c|c|c|c|c|c|}
\hline & & \multicolumn{6}{|c|}{ Miotic Therapy } \\
\hline & & \multicolumn{2}{|c|}{ At some time } & \multicolumn{2}{|c|}{ Never } & \multicolumn{2}{|l|}{ Total } \\
\hline \multicolumn{2}{|c|}{ Change in $V F C$} & & $n$ & & $n$ & & $n$ \\
\hline \multirow{3}{*}{ 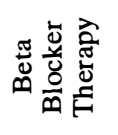 } & $\begin{array}{l}\text { At some } \\
\text { time }\end{array}$ & $+\underset{* *}{0.29}(0.47)$ & 24 & $-1.73(0.44)$ & 16 & $-0.12(0.34)$ & 40 \\
\hline & Never & $-1.37(0.46)$ & 41 & $-0.39(0.29)$ & 38 & $-0.90(0.28)$ & 79 \\
\hline & Total & $-0.75(0.35)$ & 65 & $-0.49(0.24)$ & 54 & $-0.63(0.22)$ & 119 \\
\hline \multicolumn{8}{|c|}{ Presenting IOP mm Hg } \\
\hline \multirow{3}{*}{ 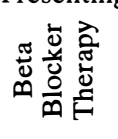 } & $\begin{array}{l}\text { At some } \\
\text { time }\end{array}$ & $25.1(1.1)$ & 23 & $24.1(1.1)$ & 16 & $24.7(0.8)$ & 39 \\
\hline & Never & $22.7(0.8)$ & 41 & $23.1(0.5)$ & 38 & $22.9(0.5)$ & 79 \\
\hline & Total & $23.6(0.6)$ & 64 & $23.4(1.5)$ & 54 & $23.5(0.4)$ & 118 \\
\hline \multicolumn{8}{|c|}{ Mean treated IOP $\mathrm{mm} \mathrm{Hg}$} \\
\hline \multirow{3}{*}{ 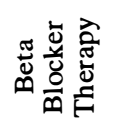 } & $\begin{array}{l}\text { At some } \\
\text { time }\end{array}$ & $21.0(0.6)$ & 24 & $20.3(0.8)$ & 16 & $20.7(0.5)$ & 40 \\
\hline & Never & $19.2(0.4)$ & 38 & $20.7(0.4)$ & 37 & $20.0(0.3)$ & 75 \\
\hline & Total & $19.9(0.3)$ & 62 & $20.6(0.4)$ & 53 & $20.2(0.2)$ & 115 \\
\hline
\end{tabular}

${ }^{*}$ SE Standard errors (SE) are given in parentheses.

${ }^{* *}$ In the group prescribed a miotic $\mathrm{p}<0.05$ for the difference between those ever given a beta blocker and those never given this treatment.

results for CSG and the right eye. The final initial VFC, fell by 0.57 units per year of the VFC was expressed in terms of $0.86 \times$ the follow up and by 0.17 units per year of age,

Table IV Unadjusted change in visual field coefficient $\left(S E^{*}\right)$ in left eyes with ocular hypertension according to whether or not treatment was given with miotics or beta blockers at some time. Corresponding presenting and mean treated intraocular pressures in $\mathrm{mmHg}$ are also recorded

\begin{tabular}{|c|c|c|c|c|c|c|c|}
\hline \multirow{3}{*}{\multicolumn{2}{|c|}{ Change in $V F C$}} & \multicolumn{6}{|c|}{ Miotic Therapy } \\
\hline & & \multicolumn{2}{|c|}{ At some time } & \multicolumn{2}{|c|}{ Never } & \multicolumn{2}{|c|}{ Total } \\
\hline & & & $n$ & & $n$ & & $n$ \\
\hline \multirow{3}{*}{ 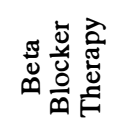 } & $\begin{array}{l}\text { At some } \\
\text { time }\end{array}$ & $-0.43(0.45)$ & 27 & $-0.19(0.49)$ & 16 & $-0.34(0.33)$ & 43 \\
\hline & Never & $-0.78(0.45)$ & 43 & $-0.31(0.37)$ & 46 & $-0.54(0.29)$ & 89 \\
\hline & Total & $-0.64(0.32)$ & 70 & $-0.28(0.30)$ & 62 & $-0.47(0.22)$ & 132 \\
\hline \multicolumn{8}{|c|}{ Presenting IOP $\mathrm{mm} \mathrm{Hg}$} \\
\hline \multirow{3}{*}{ 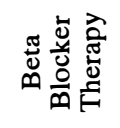 } & $\begin{array}{l}\text { At some } \\
\text { time }\end{array}$ & $25.9(1.1)$ & 26 & $24.5(1.3)$ & 16 & $25.4(0.8)$ & 42 \\
\hline & Never & $22.7(0.8)$ & 42 & $21.9(0.5)$ & 46 & $22.3(0.5)$ & 88 \\
\hline & Total & $23.9(0.7)$ & 68 & $22.5(0.5)$ & 62 & $23.3(0.4)$ & 130 \\
\hline \multicolumn{8}{|c|}{ Mean treated IOP mm Hg } \\
\hline \multirow{3}{*}{ 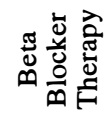 } & $\begin{array}{l}\text { At some } \\
\text { time }\end{array}$ & $21.2(0.5)$ & 27 & $20.7(0.8)$ & 16 & $21.0(0.4)$ & 43 \\
\hline & Never & $19.2(0.4)$ & 39 & $20.6(0.4)$ & 44 & $19.9(0.3)$ & 83 \\
\hline & Total & $20.0(0.3)$ & 66 & $20.6(0.3)$ & 60 & $20.3(0.2)$ & 126 \\
\hline
\end{tabular}

* SE Standard errors (SE) are given in parentheses. 
Table $\mathbf{V}$ Regression analysis of final visual field coefficients of eyes with CSG or $O H$ in the KCH glaucoma database

\begin{tabular}{|c|c|c|c|c|}
\hline & \multicolumn{2}{|c|}{$C S G$} & \multicolumn{2}{|c|}{$\mathrm{OH}$} \\
\hline & Right eye & Left eye & Right eye & Left eye \\
\hline $\begin{array}{l}\text { First follow-up field coefficient } \\
\text { units }[(4 \mathrm{~dB}+1) \times 10]\end{array}$ & $\underset{* * *}{0.86(0.03)}$ & $\underset{* * *}{0.79}(0.03)$ & $\underset{* * *}{0.93(0.10)}$ & $\underset{* * *}{0.91(0.07)}$ \\
\hline Follow-up duration (years) & $-0.57(0.31)$ & $-0.55(0.33)$ & $-0.35(0.33)$ & $0.03(0.33)$ \\
\hline Age (years) & $-\underset{* * *}{-0.17}(0.04)$ & $-\underset{* * *}{0.19}(0.04)$ & $-0.07(0.07)$ & $-\underset{*}{0.15}(0.06)$ \\
\hline $\operatorname{Sex}(F=1, M=0)$ & $0.53(0.84)$ & $-1.17(0.93)$ & $-3.26(1.33)$ & $-\underset{*}{-2.79}(1.27)$ \\
\hline $\begin{array}{l}\text { miotics at first follow-up visit } \\
\quad(\text { yes }=1, \text { no }=0)\end{array}$ & ${ }_{* *}^{3.41}(1.23)$ & $1.13(1.31)$ & $\underset{* * *}{8.56(2.07)}$ & $\underset{* * *}{7.08(1.73)}$ \\
\hline Miotics at last follow-up & $-3.33(1.30)$ & $-\frac{3.25}{*}(1.37)$ & $\underset{*}{-3.81(1.79)}$ & $\begin{array}{c}-4.91(1.99) \\
*\end{array}$ \\
\hline Duration of miotic treatment (years) & $-0.44(0.33)$ & $-0.06(0.37)$ & $-0.87(0.45)$ & $-0.64(0.45)$ \\
\hline $\begin{array}{l}\text { Duration of B blocker treatment } \\
\text { (years) }\end{array}$ & $\begin{array}{l}0.86(0.34) \\
*\end{array}$ & $0.63(0.38)$ & $1.09(0.57)$ & $0.73(0.48)$ \\
\hline Constant & $14.21(3.68)$ & $18.27(3.86)$ & $8.24(7.99)$ & $13.05(5.81)$ \\
\hline
\end{tabular}

${ }^{* * *} \mathrm{p}=<0.001,{ }^{* *} \mathrm{p}=<0.01,{ }^{*} \mathrm{p}=<0.05$.

was higher by 0.53 units if the patient was female, fell by 3.33 units if the patient was on a miotic at the end of follow up (and increased as expected by a similar amount if they had been on a miotic at presentation presumably due to miotics reducing the VFC by making the pupil area smaller). For every year on a miotic the VFC also fell by 0.44 units per year but this was not statistically significant. For every year on a beta blocker, however, the VFC increased by 0.86 units $(\mathrm{p}<0.05)$. If we assume that a patient did not receive a miotic yet did receive a beta blocker, then the annual change in VFC according to this model was +0.86 (due to beta blockers) less 0.57 due to the passage of time, the net change +0.29 is given in Table VI. (If we include the age term $(-0.17)$ patients becoming one year older over a one year duration of follow up, the net change would be +0.12 units per year).

Similar results were obtained for CSG in the left eyes and for $\mathrm{OH}$ in both eyes. These results, however, did not quite reach conventional levels of statistical significance for the benefits of beta blockers although all indicate a tendency to improve ( 0.63 to 1.09 units per year of use of beta blockers).

Other factors were also consistent, for example, a deterioration of 0.07 to 0.19 units per year of age and a lower VFC when miotics were given. The effect of duration of follow up was small in $\mathrm{OH}$ and the sex effect was variable.

Table VI summarises the above analyses and records the net effect of the use of beta blocker therapy. There was an estimated increase in VFC of 0.29 units per year for right eyes and 0.08 units per year for left eyes in CSG and of 0.74 units per year for right eyes and 0.76 units per year for left eyes in $\mathrm{OH}$. After further adjusting for effects of ageing, the effect of a beta blocker still resulted in a theoretical increase in VFC except in left eyes in CSG where the deterioration was small (0.11/year).

\section{Discussion}

The basis of treatment of chronic simple glaucoma at present is the reduction of intraocular pressure. The degree to which this can be effective is limited by the extent to which the level of the intraocular pressure contributes to loss of visual function. This is usually assessed by changes in the sensitivity of the visual field. It is important to be aware that many factors are involved in glaucomatous optic atrophy 
Table VI The change in adjusted visual field coefficient per year

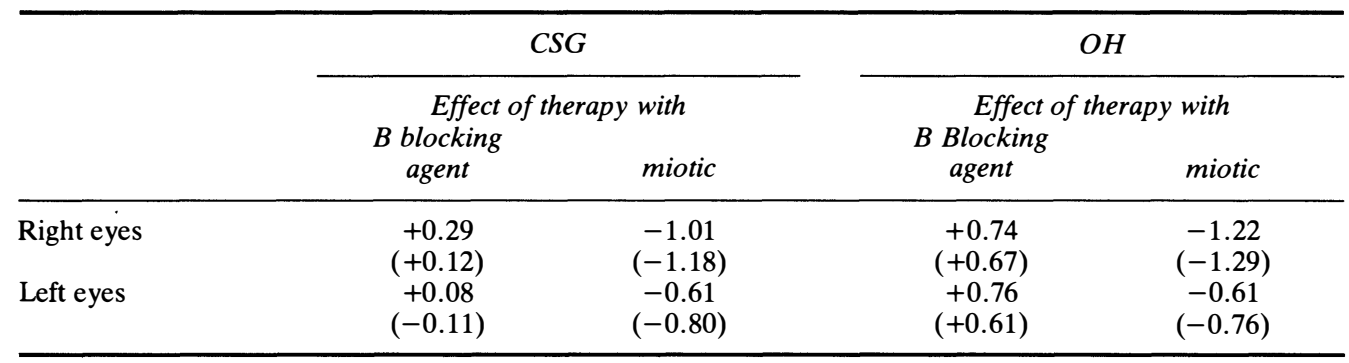

The table records the net change in VFC per year due to a one year treatment with either a topical beta blocking agent or a topical miotic for CSG and OH for right and left eyes. The figures in parentheses also take account of the patient ageing by one year.

and that field changes are a relatively late sign of optic nerve damage of this type. ${ }^{4}$ The analysis concerns mean visual field sensitivity and local changes of sensitivity are not indicated. However, in these patients the changes in visual fields have tended to be generalized. ${ }^{5} \mathrm{~A}$ search for earlier signs of impaired visual function such as reduced contrast sensitivity ${ }^{6,7}$ or colour vision defect is in progress. ${ }^{8,9,10}$

Impairment of the optic nerve in the region of the optic disc depends on various influences which are incompletely understood but are partly dependent on racial ${ }^{11,12}$ and other genetic factors. ${ }^{13-15}$ Other variables include the intraocular pressure $\mathrm{e}^{16-19}$ and the anatomy and blood supply of the optic nerve head and the nature of its connective tissue support. ${ }^{20,21}$ In other analyses we have presented evidence to show that an elevated intraocular pressure is relevant to visual field loss in CSG. ${ }^{2,22-24}$

We also considered it important to try to discover whether agents which undoubtedly lower the intraocular pressure and which, therefore, might be expected to have a favourable effect on field loss in CSG, do or do not also adversely affect other factors, such as the circulation of the optic disc, because any adverse effect may reduce or neutralize their usefulness in maintaining the visual field. This has been suggested ${ }^{25}$ and would mean that the enormous effort and expense in developing beta blocking agents to lower intraocular pressure, and thereby help to preserve the sight of CSG patients, might have been in vain.

The present investigation has compared the progress of the visual field in patients with CSG and $\mathrm{OH}$ treated with a topical miotic alone and a miotic with the addition of a topical beta blocking agent. The unadjusted figures indicate that the addition of topical timolol therapy in a large group of patients with CSG and a smaller group with $\mathrm{OH}$ receiving pilocarpine drops resulted in a reduced rate of visual field loss. This was statistically significant in both the right and the left eyes of those with CSG. In the case of $\mathrm{OH}$ the same trend was noted but only the findings for the right eyes were statistically significant. The beneficial effect of beta blockade in right eyes was not due to achieving a lower mean treated intraocular pressure (Table I). However, the small number of patients who received treatment with neither drug and had a good visual field outcome, did have a low mean IOP during follow up $(15.5 \mathrm{mmHg})$. On the other hand the group who had both treatments had a higher presenting intraocular pressure of $24.8 \mathrm{mmHg}$ reduced by a mean of $5.4 \mathrm{mmHg}$ compared with a lower presenting intraocular pressure of $19.5-23.2 \mathrm{mmHg}$ and a mean reduction of 3.9 to $4.7 \mathrm{mmHg}$ in the other three groups. The same tendency was observed for left eyes with chronic simple glaucoma (Table II) and for both eyes with ocular hypertension (Tables III and IV). The effect of these differences in intraocular pressure on the visual field in the groups is difficult to assess. The results suggest that a greater reduction in intraocular pressure is more important than a lower mean treated intraocular pressure but there may be other explanations, such as reduction in diurnal variation or better compliance in the case of beta blocker therapy. There is no strong evidence for the effect of 
beta blockers being due to mechanisms over and above the intraocular pressure changes although these are of course possible. The mathematical model using multiple regression techniques to allow for several relevant variables showed a positive association between the maintenance of the VFC and the duration of beta blocker treatment. This association was present in the right and the left eyes for both $\mathrm{CSG}$ and $\mathrm{OH}$ and statistical significance was achieved for right eyes in CSG.

In a smaller but prospective controlled study (unpublished data) of CSG it has been shown that the mean intraocular pressure in a timolol treated group was never more than $1-2 \mathrm{mmHg}$ lower than in the pilocarpine treated group and the difference only reached statistical significance on one occasion. The diurnal range was also similar in both treatment groups.

\section{Conclusions}

The results do not support the theoretical possibility that the vascular effects of topical sympathetic beta blocking agents might counteract the mean beneficial effect that their lowering of the IOP may have on visual field survival in CSG. It is important for CSG management to appreciate that, on the contrary, the present analysis indicates that compared with patients on miotic treatment alone, even though the effect of changes in intraocular pressure are difficult to assess, there is in practice a relative mean preservation of visual field in those patients receiving both miotic and timolol drops.

We should like to thank the King's College Hospital Research Committee, the International Glaucoma Association and the S.E. Thames Regional Computer Centre for assistance in developing and operating the Glaucoma Database. Such work requires the invaluable cooperation of all members of the Ophthalmic Department at King's College Hospital to whom we are greatly indebted and especially to Mr Roger Coakes and Dr Patricia Reynolds.

We thank the Medical Department of Merck, Sharp \& Dohme, for financial support.

\footnotetext{
References

${ }^{1}$ Crick RP: Prevention of blindness from glaucoma using the King's College Hospital computerised problem orientated medical record. BrJOphthalmol 1975, 59: 236-48.
}

${ }^{2}$ Daubs J and Crick RP: Epidemiological analysis of the King's College Hospital glaucoma data. Res and Clin Forums 1980, 2.1: 41-59.

${ }^{3}$ Hollows FC and Graham PA: The Ferndale Glaucoma Survey. In Hunt LB ed. 'Glaucoma'. Edinburgh and London: E and S Livingstone 1966: 24-44.

${ }^{4}$ Quigley JA, Addicks EM, Green WR: Optic nerve damage in human glaucoma. Arch Ophthalmol 1982, 100, 135-46.

${ }^{5}$ Crick RP, Vogel R, Newson RB, Shipley MJ, Blackmore H, Palmer A, Bulpitt CJ: The visual field in chronic simple glaucoma and ocular hypertension; its character, progress, relationship to the level of intraocular pressure and response to treatment. Eye 1989, 3: 536-46.

${ }^{6}$ Arden GB: Visual loss in patients with normal visual acuity. Trans Ophthalmol Soc UK 1978, 98: 219-31.

${ }^{7}$ Atkin A, Bodis-Wollner I, Wolkstein M, Moss A, Podos SM: Abnormalities of central contrast sensitivity in glaucoma. Am J Ophthalmol 1979, 88: 105-211.

${ }^{8}$ François $\mathrm{J}$ and Verriest G: Les dyschromatopsies acquises dans le glaucome primaire. Ann Oculist 1959, 192: 191-9.

${ }^{9}$ Lakowski $\mathrm{R}$ and Drance SM: Acquired dyschromatopsia-the earliest functional loss in glaucoma. Doc Ophthalmol Proc 1979, 19: 159-65.

${ }^{10}$ Alvarez SL and Mills KB: Spectral and flicker sensitivity in ocular hypertension and glaucoma. Res Clin Forums. 1985, 7(1): 83-94.

${ }^{11}$ Wallace J and Lovell HG: Glaucoma and intraocular pressure in Jamaica. Am J Ophthalmol 1969, 67: 93-100.

${ }^{12}$ Wilensky JT, Gandhi N, Pan T: Racial factors in open angle glaucoma. Am J Ophthalmol 1979, 67: 93-100.

${ }^{13}$ Kellerman L and Posner A: The value of heredity in the detection and study of glaucoma. Am J Ophthalmol 1955, 40: 681-5.

${ }^{14}$ Miller SJH and Paterson GD: Studies in glaucoma relatives. Br J Ophthalmol 1962, 46: 513-6.

${ }^{15}$ Armaly MF: On the distribution of applanation pressure. (1) Statistical features and the effect of age, sex and family history of glaucoma. A Arch Ophthalmol 1965, 73: 11-18.

${ }^{16}$ Leydhecker W: Die zuverlassigkeit der diagnose des glaucoma simplex in fruhstadium. Doc Ophthalmol 1966, 20: 214-29.

${ }^{17}$ Armaly MF: Ocular pressure and visual fields-a ten year follow up study. Arch Ophthalmol 1969, 81: 25-40.

${ }^{18}$ David R, Livingstone D, Luntz MH: Ocular hypertension-a long term follow up of treated and untreated patients. Br J Ophthalmol 1977, 61: 668-74.

${ }^{19}$ Drance SM, Wheeler C, Patullo M: Uniocular open angle glaucoma. Arch Opthalmol 1982, 100: 135-46.

${ }^{20}$ Hayreh SS: Pathogenesis of optic nerve damage and visual field defects in glaucoma. Doc Ophthalmol 1980, 22: 89-110.

${ }^{21}$ Maumenee AE: The pathogenesis of visual field loss 
in glaucoma. In Brockenhurst RJ, Boruchoff SA, Hutchinson BT, and Lessel S, eds. Controversy in ophthalmology. Philadelphia: WB Saunders 1977, 301-311.

${ }^{22}$ Vogel R, Crick RP, Newson RB, Shipley M, Blackmore $\mathrm{H}$, Bulpitt $\mathrm{CJ}$ : The association between intraocular pressure and loss of visual field in chronic simple glaucoma. Res and Clin Forums 1985, 7(i): 63-7.

${ }^{23}$ Crick RP, Vogel R, Newson RB, Shipley M, Blackmore $\mathrm{H}$, Bulpitt CJ: Relationship between intraocular pressure and visual field progress in chronic simple glaucoma and ocular hypertension. Glaucoma 1985, 7: 208-19.

${ }^{24}$ Vogel R, Crick RP, Newson RB, Shipley M, Blackmore $\mathrm{H}$, Bulpitt $\mathrm{CJ}$ : The association between intraocular pressure and loss of visual field in chronic simple glaucoma. Br J Ophthalmol 1990, 74: 3-6.

${ }^{25}$ Drance SM and Flammer J: Some effects of antiglaucoma drugs on visual function. In Drance SM, Neufield AH, eds. 'Glaucoma: Applied pharmacology in medical treatment'. Orlando, Grune and Stratton, 1984; 569-576. 